\title{
Review \\ Ductal approaches to assessment and management of women at high risk for developing breast cancer
}

\author{
Imogen Locke ${ }^{1}$, Gillian Mitchell ${ }^{2}$ and Rosalind Eeles ${ }^{1}$
}

\author{
1Translational Cancer Genetics Team \& Cancer Genetics Unit, The Institute of Cancer Research and The Royal Marsden NHS Trust, Sutton, \\ Surrey, UK \\ ${ }^{2}$ Family Cancer Centre, Peter MacCallum Cancer Centre, Victoria, Australia \\ Correspondence: Imogen Locke (e-mail: imogen.locke@icr.ac.uk)
}

Published: 26 January 2004

Breast Cancer Res 2004, 6:75-81 (DOI 10.1186/bcr759)

(C) 2004 BioMed Central Ltd (Print ISSN 1465-5411; Online ISSN 1465-542X)

\begin{abstract}
The ductal approach to breast cancer, encompassing nipple aspiration, ductal lavage and duct endoscopy, allows assessment of breast ductal epithelial cells and their local microenvironment in a graded process of increasing invasiveness. Samples of ductal epithelial cells sufficient for cytological diagnosis may be safely collected, titres of individual proteins showing variation with breast cancer status may be measured, and abnormal pathology within the breast ducts may be directly visualized. Identification of surrogate molecular markers may facilitate early breast cancer detection, in conjunction with cytological assessment, and be useful for individual prediction of breast cancer risk and assessment of treatment response. However, the sensitivity and specificity of the ductal approach require further evaluation. The small quantities of nipple aspiration fluid available for analysis, and difficulties identifying and cannulating ducts remain important limitations of these techniques.
\end{abstract}

Keywords: breast carcinoma, ductal lavage, high-risk women, nipple aspiration, risk assessment

\section{Introduction}

In the adult nonpregnant, nonlactating breast, fluid is secreted into the ducts and may contain exfoliated ductal epithelial cells along with foam cells, lymphocytes and neutrophils. Foam cells, thought to be of macrophage lineage, are the most abundant cells found within ductal fluid. They demonstrate CD68 macrophage-specific antibody staining and are usually negative for cytokeratin markers $[1,2]$.

The intraduct approach is an umbrella term for several different techniques, including nipple aspiration (NA), ductal lavage (DL) and duct endoscopy (DE), that allow sampling of breast fluid and exfoliated epithelial cells - the cells at risk for malignant transformation. DE also permits direct visualization of the epithelial lining of the milk ducts. NA and DL are minimally invasive techniques, whereas $D E$ involves the cannulation of the mammary duct system by a fibreoptic ductoscope with an outer diameter typically less than $1 \mathrm{~mm}$.
Women may be at significantly increased lifetime risk for developing breast cancer because they have a significant family history of breast or ovarian cancer or a number of personal history factors. They may also be at heightened risk because of carriage of a known deleterious mutation in a highly penetrant breast cancer predisposition gene such as BRCA1 or BRCA2, or other mutations in rarer susceptibility alleles in genes including TP53, PTEN and the recently described lower penetrance 1100 delC mutation in the cell cycle checkpoint kinase gene (CHEK 2) [3-6]. Carriers of mutations in BRCA1/2 have a lifetime risk for developing breast cancer of $60-85 \%$, whereas germ-line mutations in TP53 confer a lifetime risk for breast cancer as high as 90\% [7-9].

Currently, women who carry mutations in high-risk breast cancer predisposition genes must make a difficult choice between regular surveillance, risk-reducing surgery, or taking part in trials of chemopreventive agents. The effec-

$\mathrm{ADH}=$ atypical ductal hyperplasia; CEA = carcinoembryonic antigen; $\mathrm{DE}=$ duct endoscopy; $\mathrm{DL}=$ ductal lavage; FISH = fluorescent in situ hybridization; $\mathrm{MMP}=$ matrix metalloproteinase; $\mathrm{MSP}=$ methylation-specific polymerase chain reaction; $\mathrm{NA}=$ nipple aspiration; $\mathrm{NAF}=$ nipple aspiration fluid; SELDI = surface-enhanced laser desorption and ionisation; TOF = time of flight. 
tiveness of surveillance is uncertain and there are concerns about the high incidence of interval breast cancers, particularly in women under the age of 40 years and in $B R C A 1 / 2$ carriers [10]. Another concern is the potential mutagenicity of repeated screening mammography in women who have an inherited impairment in the ability to repair double-stranded DNA breaks.

There is considerable interest in alternative screening tools in this group of women, such as breast magnetic resonance imaging [11]. The ductal approach is currently being evaluated as a reproducible method of gaining minimally invasive access to epithelial cells. Subsequent cytological and/or molecular analysis of these cells may inform individual breast cancer risk assessment or even permit early diagnosis of cancer while avoiding the use of ionizing radiation.

\section{Application of the ductal approach in high- risk women}

Identification of high-risk women and estimation of their breast cancer risk is currently based on the use of validated mathematical models such as the Gail and the Claus models [12,13]. The intraduct approach, with its ability to examine directly those cells that are most at risk for malignant transformation and their surrounding milieu, intuitively offers the potential for refining personal risk estimates, thus aiding clinical management decisions, and it may facilitate detection of early breast cancer. This would be particularly useful in counselling women at high risk for developing breast cancer, in whom epidemiological models of risk assessment and current screening tools have well recognized limitations $[10,14]$. New insights into the interactions within breast tissue that are involved in the multistep process of carcinogenesis may also be gained.

Chemoprevention is an expanding area of interest, although four trials of tamoxifen chemoprevention in women at increased risk for developing breast cancer [15-18] yielded conflicting results. Trials to assess the efficacy of chemopreventive drugs take many years to perform when the development of breast cancer or breast cancer mortality are used as the primary end-points. Markers within ductal fluid or cytogenetic changes within ductal epithelial cells that directly reflect early response to therapy (biomarkers) would provide a more immediate and desirable end-point for chemoprevention trials in high-risk women.

\section{Nipple aspirate cytology}

NA is the simplest and least invasive of the methods for sampling the intraduct environment. Following cleansing with an alcohol impregnated swab, the woman is asked to massage her breast from the base toward the nipple. Suction is then exerted on the nipple using a modified rate fluid (NAF) will appear on the nipple surface that may be collected into capillary tubes. The sample from one breast is generally pooled as a consequence of the small volumes of NAF produced.

Cytological assessment of spontaneous nipple secretions and NAF are not new techniques; Papanicolaou and coworkers [19] demonstrated that nipple fluid could be aspirated from healthy nonlactating, nonpregnant women, and his cytopathological examination of samples from 613 breasts of 412 women without breast symptoms revealed one occult breast carcinoma. Similarly, Sartorius and coworkers [20] reported the diagnosis, by nipple aspirate cytology alone, of seven clinically and mammographically occult carcinomas among 1503 women.

NA does not yield fluid in all women, with investigators reporting success rates of between 38\% and $99 \%$ $[21,22]$. Typically, $20-30 \mu$ of NAF may be collected but reported volumes range from $1 \mu \mathrm{l}$ to over $200 \mu \mathrm{l}[23,24]$. The proportion of specimens containing adequate numbers of epithelial cells for cytological diagnosis ( $>10$ cells) is highly variable, but success rates among fluid-yielders of up to $95 \%$ have been reported [23]. Aspirates from women with clinical evidence of benign breast disease tend to be more cellular [25]. The percentage of successful aspirations is greatest in women aged between 35 and 50 years, and factors associated with increased yield of nipple aspiration include early age at menarche, Caucasian (as opposed to Asian) ethnicity, and a history of parity or lactation [24]. The effects of age appeared to be independent of menopausal status. Prior breast irradiation has been reported to reduce the rate of successful nipple aspiration [23].

Although early work demonstrated occasional detection of malignant cells, one of the limitations of nipple aspirate cytology as a diagnostic tool in early breast cancer is the low percentage of specimens that contain cancer cells, even when the aspirate is obtained from a known cancerbearing breast; sensitivities of $4 \%$ and $21 \%$ were reported in two studies $[26,27]$. The low sensitivity may relate in part to the anatomical obstruction of the breast ducts by tumour, preventing exfoliated malignant cells from reaching the nipple and/or breaching the integrity of the duct to permit leakage of ductal fluid. The sensitivity of NA cytology in detecting preinvasive breast disease has been reported to be higher than in established invasive breast cancer [26].

\section{Ductal lavage cytology}

$\mathrm{DL}$ is a minimally invasive procedure in which a fine plastic microcatheter is threaded into the nipple duct orifices to a maximum depth of $1.5 \mathrm{~cm}$. NA is used to identify fluid-producing ducts, because these are the most likely to be successfully cannulated. Normal saline is instilled through the 
catheter, after which the effluent is recovered by simultaneous compression of the breast and aspiration. Although more invasive than NA, DL has the advantage of allowing collection of duct-specific samples. However, failure to cannulate successfully all nipple ducts is a limitation of this technique, particularly if it were to be used as a screening tool for breast cancer.

In a multicentre trial of 507 women at increased risk for breast cancer [28], DL was compared with NA with respect to safety, tolerability and ability to detect atypical epithelial cells. High-risk women were defined as a 5-year Gail risk for developing invasive breast cancer of at least $1.7 \%$, a prior history of invasive breast cancer or carcinoma in situ, or known carriage of a mutation in either the $B R C A 1$ or BRCA2 gene (although only three women were $B R C A 1$ or BRCA2 mutation carriers, accounting for $<1 \%$ of the study population). Of the nipple aspirate samples $27 \%$ were adequate for cytological diagnosis (defined as $>10$ epithelial cells per slide), as compared with $78 \%$ of $\mathrm{DL}$ samples. The median cellularity of $\mathrm{DL}$ specimens was 135000 per duct (range 43-492000), and DL specimens contained significantly more epithelial cell clusters than did the corresponding NAF, in which the median epithelial cell count per breast was 120 (range 10-74300). The comparative detection rates of marked atypia for DL and NA were $6 \%$ and $3 \%$, respectively. Mild atypia (some atypical features such as nuclear pleiomorphism, increased nuclear:cytoplasmic ratio and loss of cellular cohesiveness in an otherwise benign aspirate) was detected in $17 \%$ of the DL samples, as compared with $6 \%$ of the NA samples. Malignant cells were found in nipple aspirates from two women $(<1 \%)$, and these were the same two women who were found to have malignant cells on DL.

\section{Duct endoscopy}

Breast DE is the most recent of the intraduct techniques to have been developed, and it permits direct visualization of the proximal ductal tree. It is currently limited by the technical difficulties of reliably identifying duct orifices and obtaining tissue biopsies. The application of DE for routine outpatient screening of high-risk women has not been assessed, and indeed much remains unknown about the sensitivity and specificity of DE for detection of early breast cancer. Ductal washing can be harvested during ductoscopy and cytopathological findings correlated with subsequent histopathogy in women undergoing breast surgery [29]. Images of ductal abnormalities may also be recorded using video. An application of DE being currently explored is its use to guide the extent of lumpectomy for management of breast cancer. DE has been reported to highlight substantial amounts of intraductal disease not suspected on preoperative mammography and ultrasound, resulting in the reduction of the surgical positive margin rate from $23.5 \%$ to $5 \%$ [30].

\section{The prognostic value of ductal epithelial cell atypia}

In a retrospective cohort study, the relative risk for developing invasive breast carcinoma in women found to have atypical ductal hyperplasia (ADH) on breast biopsy is 4.3 times that in the general population, and when combined with a positive family history the relative risk for invasive breast cancer rises to 9.7 [31]. Similarly, in a nested case-control study [32] the relative risk for breast cancer in women with $\mathrm{ADH}$ on biopsy was 4.3 , and there was a synergistic increase in breast cancer relative risk to 22 when $\mathrm{ADH}$ was combined with a first-degree family history of breast cancer.

Wrensch and coworkers [33] studied the long-term prognostic significance of nipple aspirate cytology for breast cancer development prospectively in a cohort of 2701 Caucasian volunteer women from the San Francisco Bay area who were followed for a median of 12.7 years. The relative risk for breast cancer in women with cellular atypia in NAF was fivefold higher than in women who did not yield fluid and three times higher than in women with normal NAF cytology. The relative risk was even greater for women under 55 years of age. Women with atypia and a firstdegree family history of breast cancer were sixfold more likely to develop breast cancer compared with women with atypia but no family history of breast cancer. Extended follow up after a median of 21 years of an expansion of this cohort of women [34] confirmed these findings, with an increased relative risk for developing breast cancer of 2.8 for women with atypia compared with women from whom nipple aspirate fluid could not be obtained.

Random periareolar fine needle aspiration cytology is another method that has been developed to sample the breast ductal epithelium. In a study of 484 women at increased risk for developing breast cancer [35], both hyperplasia with atypia and Gail model risk estimates were found to be independent predictors of breast cancer development, with atypia increasing the relative risk by a factor of five. In summary, the relative risks for developing breast cancer associated with cytological atypia, whether identified by NA or by random periareolar fine needle aspiration, are similar to the increased risk for breast cancer conferred by the histopathological finding of $\mathrm{ADH}$ on breast biopsy. However, the long-term significance for individuals of atypia within DL fluid, particularly mild cellular atypia, is yet to be clarified. The ability of the ductal approach to detect early breast cancer using cytological criteria alone appears to be low and current research is directed toward identifying molecular markers that, in combination with cell morphology, may be of utility in the assessment and management of women at increased risk for developing breast cancer. It may be that the ductal approach is most useful in breast cancer risk prediction rather than detection of early breast cancer. 


\section{Candidate biomarkers in nipple aspiration fluid}

One approach to the search for complementary biomarkers of breast cancer risk has been to measure individual molecules in NAF, often proteins with established value as serum tumour markers, and to study their variation with disease status. Prostate-specific antigen, a serine protease, is a useful serum marker for the diagnosis and management of prostate cancer, and was recently found to be expressed at high levels in NAF [36-38]. Although Sauter and coworkers [38] reported lower levels of prostate-specific antigen in NAF from breasts with cancer or precancerous mastopathy, others have failed to show a similar variation with tumour status [39]. Carcinoembryonic antigen (CEA) is measurable in NAF at considerably higher concentrations than in serum, and in one study [39] CEA titres were significantly higher in untreated cancerous breasts than in tumour-free breasts, giving a sensitivity for CEA as a candidate biomarker for breast cancer detection of $48 \%$ and a specificity of $75 \%$. In a study of women with unilateral invasive breast cancer [40], levels of expression of the HER-2/neu extracellular domain in NAF were found to be significantly higher in the breast with cancer than in the contralateral normal breast, but this difference was restricted to women with HER-2/neu overexpressing tumours.

Growth factors play important roles in the control of epithelial cell proliferation, and they are therefore an attractive potential source of biomarkers for evaluation. It is feasible to measure epidermal growth factor and transforming growth factor- $\alpha$ in NAF from healthy women $[41,42]$. Angiogenic growth factors, including basic fibroblast growth factor and vascular endothelial growth factor, have been the subject of recent studies; high levels of the former in NAF exhibit an association with breast cancer status independent of race and menopausal status $[43,44]$. The matrix metalloproteinases (MMPs), which are involved in degradation and remodelling of the extracellular matrix and in tumour invasion and metastasis, were recently measured in NAF [45]; higher mean concentrations of MMP-2 and MMP-9 were present in fluid from cancer-containing breasts than in fluid from benign or healthy breasts.

There is a vast array of individual molecules worthy of further investigation as candidate biomarkers of malignancy. These are involved at all stages of tumour genesis and progression from self-sufficiency in growth signals, evasion of apoptosis, and sustained angiogenesis, to tissue invasion and metastasis. Limitations in sensitivity and specificity of individual markers may be partially overcome by considering a panel of molecules that are individually predictive of breast cancer risk. The degree of overlap between ranges in cancerous and healthy breasts, together with the small amounts of NAF available for multi- ple directed assays, are other difficulties that make global approaches to biomarker discovery such as proteomics attractive alternative strategies.

\section{Genetic instability in ductal epithelial cells}

The presence of numerical aberrations of chromosomes 1 , 8 and 17 has been correlated with the multistage process of breast cancer tumourigenesis and progression. These may precede morphological changes in the ductal epithelial cells [46-49]. Fehm and coworkers [47] found that $92 \%$ of 74 primary breast cancers showed aneusomy for chromosomes 1, 8 or 17, whereas Botti and coworkers [46] demonstrated aneusomy of chromosomes 1 and 17 in fresh imprints of primary breast cancers and in biopsies of adjacent uninvolved tissue in $66.7 \%$ of patients. Similar patterns of chromosomal aneusomy were seen in the contralateral breasts of women who had previously had breast cancer, suggesting a field effect of genomic instability compared with benign controls [46].

The sensitivity and specificity for breast cancer detection of conventional cytology, in comparison with cytogenetic findings of interphase fluorescent in situ hybridization (FISH) using centromeric probes, were evaluated in DL fluid [50]. Cytology was abnormal in seven out of 15 evaluable ductal lavages obtained from cancerous breasts, as compared with four out of 19 evaluable lavages from paired benign cases, giving a sensitivity and specificity for cytology alone of $47 \%$ and $79 \%$, respectively. Interphase FISH showed significant gains of chromosomes 1, 8, 11 and/or 17 (more than three standard deviations greater than the mean percentage values of monosomic and polysomic cells in the benign samples) in 10 out of 14 evaluable lavages from the cancerous breasts, as compared with two of 18 samples from the benign cases, giving a sensitivity and specificity for FISH of $71 \%$ and $89 \%$, respectively.

A further study, in which cytology and FISH were applied to ductal lavage specimens, was conducted in women with nipple discharge and abnormal ductography and/or fibreoptic ductoscopy [51]. None of the samples collected from 54 benign cases showed aneusomy for chromosomes 1,11 or 17 , giving a specificity of $100 \%$, whereas aneusomy for at least one of these three chromosomes was seen in all six malignant cases examined. These studies demonstrated the feasibility of analyzing ductal epithelial cells for chromosomal abnormalities, and in the future cytogenetic findings may usefully improve the discriminatory value of cytology for the definitive diagnosis of malignancy.

\section{DNA hypermethylation as a biomarker of malignancy}

The expression of a number of genes in primary breast cancer has been shown to be silenced by hypermethyla- 
tion of promoter sequences [52,53]. Evron and coworkers [54] used methylation-specific polymerase chain reaction (MSP) to search for breast cancer-associated changes in patterns of DNA methylation. Those investigators defined a set of three genes (Cyclin D2, Twist, RARB) that were hypermethylated in $96 \%$ of invasive breast carcinomas and $57 \%$ of ductal carcinoma in situ in surgically excised specimens from women with primary breast tumours. The application of MSP to the detection of malignant epithelial cells in ductal fluid was subsequently investigated. At least one methylated marker was found in 17 out of 20 samples of the irrigation fluid from women who underwent breast $\mathrm{DE}$ immediately before definitive surgery for biopsy-proven breast cancer. DL fluid was also obtained from 56 asymptomatic high-risk women (Gail risk $\geq 1.7$, previous contralateral breast cancer, or carrier of a BRCA1 or BRCA2 gene mutation), in whom there were no suspicious findings on mammography or physical examination, and analyzed for methylated markers. Forty-five samples were classified as benign, five samples were classified as mildly atypical, and six samples exhibited severe atypia or were frankly malignant by cytopathological criteria alone. Four out of the six severely atypical or malignant samples were also identified by MSP (sensitivity 67\%), whereas only five out of the 45 benign samples were positive for methylated markers (specificity 89\%). Two women who had both abnormal cytology and at least one methylated marker in ductal lavage fluid were subsequently found to have pathologically confirmed breast cancer.

\section{Proteomics and high-throughput biomarker discovery}

Growing interest in the global expression of proteins in biological systems (the so-called proteome) has arisen because proteins are the workhorses of most cellular functions. Unique protein expression profiles associated with disease states may reflect not only changes at the gene expression level but also post-translational modifications. High-throughput proteomic technologies are being developed, such as surface-enhanced laser desorption and ionization (SELDI). This novel form of mass spectrometry, in which proteins are selectively adsorbed to coated metal 'chips', utilizes time of flight (TOF) mass spectrometry to analyze proteins that interact with the chip surface after washing under different conditions to remove unbound protein. SELDI-TOF overcomes some of the problems of labour intensive sample separation and requires only microlitre quantities of biological fluids, but it does not provide routine peptide sequence information.

A number of recent studies have demonstrated the promising application of proteomics to samples of NAF, leading to the generation of 'fingerprints' representing proteins that are differentially expressed in cancerous breasts and normal breasts and worthy of further evaluation as biomarkers of malignancy [55-57]. Using SELDI-TOF mass spectrometry to examine NAF from 12 women with breast cancer and 15 healthy control women, proteomic patterns were identified that appeared to be discriminatory between the two groups [55]. Similarly, Sauter and coworkers [56] used the SELDI technique to perform a proteomic analysis over the $5-40 \mathrm{kDa}$ range and identified five differentially expressed protein peaks in NAF from 20 women with breast cancer and 13 women with healthy breasts, the two most discriminatory of which had molecular weights of $6500 \mathrm{Da}$ and $15940 \mathrm{Da}$. The former peak has been suggested to represent epithelin. A further differentially expressed peak of $28100 \mathrm{Da}$ has been putatively identified as a member of the kallikrein family.

A preliminary gel-based proteomics study using twodimensional PAGE detected between 1280 and 1649 separate protein spots in NAF. Up to 202 qualitative differences were found between NAF taken from the diseased breast of three women with unilateral breast cancer and the contralateral normal breast, whereas in one healthy woman only five protein spots were different between left and right breasts [57]. Progress is being made toward characterizing the full proteome of NAF, and hence the exact identification of the proteins responsible for the differential patterns seen using both gel-based and gel-free proteomic techniques. A recent report [58] definitively identified 64 proteins in the moderately abundant and abundant ranges within NAF, 15 of which were previously reported to vary with breast cancer status in serum or tumour tissue, and include among others cathepsin D and osteopontin.

\section{Conclusion}

The intraduct approach to risk assessment and early diagnosis of breast cancer in high-risk women has many theoretical attractions; however, the specificity and sensitivity of these techniques remain important limitations. Although early studies demonstrated that NA and DL are feasible and safe techniques for retrieving epithelial cells, the relationship between the various degrees of cellular atypia and the underlying process of breast cancer tumourigenesis is not completely understood. NA has the advantage of being well tolerated, easy to perform and inexpensive, but it is limited by the small amounts of aspirate available for analysis, the relatively low cellular yield and the fact that not all women are fluid yielders. DL, although more invasive, produces material that is much more cellular than NAF and allows duct-specific sampling. However, the DL fluid is diluted with a variable quantity of saline, which may complicate quantitative analysis of biomarkers. DE is the most labour intensive of the intraduct techniques with the greatest resource implications, and therefore in practice it may be best suited to the further investigation of women in whom cellular atypia has already been identified, in conjunction with clinical and radiological assessment. These complexities, along with the requirement for regular inter- 
vention and follow up, may affect compliance rates among high-risk women.

Recent developments in the fields of genomics and proteomics, and the advent of high throughput biotechnologies give hope that biomarker patterns associated with disease states will be defined. These patterns could complement the traditional cytological assessment of cell morphology, improving the predictive and diagnostic value of the intraduct approach. The intraduct approach may help to refine a personalized breast cancer risk assessment, which would be of particular importance to high-risk women who face difficult decisions about risk management options. Furthermore, sampling the ductal epithelial cells and their local microenvironment may also identify markers of early response to therapy that act as surrogate end-points in chemoprevention trials. Studies have shown early promise in identifying surrogate markers of breast cancer risk, including multiple molecules that are involved at all stages of cancer development and progression, epigenetic changes such as hypermethylation of promoter sequences, and differential patterns of protein expression. Validation of these potential molecular markers of breast cancer risk and further evaluation of the ductal approach to establish its sensitivity and specificity in detecting early breast cancer is required. The intraduct approach is beginning to show value in documenting the presence and extent of ductal epithelial proliferation within breast tissue, informing the assessment and management of high-risk women and providing new insights into the biology of breast cancer.

\section{Competing interests}

None declared.

\section{Acknowledgements}

Cancer Research UK supports the work of IL (grant reference number C5057/A3294). Breast Cancer Campaign and The Susan Love MD Foundation sponsored GM's work. The Institute of Cancer Research supports the work of RE. The authors would also like to thank Dr Timothy Blackburn and Dr Susanne Rogers for reading the manuscript and providing helpful comments.

\section{References}

1. Krishnamurthy S, Sneige N, Ordonez NG, Hunt KK, Kuerer HM: Characterization of foam cells in nipple aspirate fluid. Diagn Cytopathol 2002, 27:261-264.

2. King BL, Crisi GM, Tsai SC, Haffty BG, Phillips RF, Rimm DL: Immunocytochemical analysis of breast cells obtained by ductal lavage. Cancer 2002, 96:244-249.

3. Ford D, Easton DF, Stratton M, Narod S, Goldgar D, Devilee P, Bishop DT, Weber B, Lenoir G, Chang-Claude J, Sobol H, Teare MD, Struewing J, Arason A, Scherneck S, Peto J, Rebbeck TR, Tonin P, Neuhausen S, Barkardottir R, Eyfjord J, Lynch H, Ponder BA, Gayther SA, Zelada-Hedman M: Genetic heterogeneity and penetrance analysis of the BRCA1 and BRCA2 genes in breast cancer families. The Breast Cancer Linkage Consortium. Am J Hum Genet 1998, 62:676-689.

4. Birch JM, Hartley AL, Tricker KJ, Prosser J, Condie A, Kelsey AM, Harris M, Jones $\mathrm{PH}$, Binchy A, Crowther D: Prevalence and diversity of constitutional mutations in the p53 gene among 21 Li-Fraumeni families. Cancer Res 1994, 54:1298-1304.
5. Liaw D, Marsh DJ, Li J, Dahia PL, Wang SI, Zheng Z, Bose S, Call KM, Tsou HC, Peacocke M, Eng C, Parsons R: Germline mutations of the PTEN gene in Cowden disease, an inherited breast and thyroid cancer syndrome. Nat Genet 1997, 16:64-67.

6. Meijers-Heijboer $\mathrm{H}$, van den Ouweland A, Klijn J, Wasielewski M, de Snoo A, Oldenburg R, Hollestelle A, Houben M, Crepin E, Veghel-Plandsoen M, Elstrodt F, van Duijn C, Bartels C, Meijers C, Schutte M, McGuffog L, Thompson D, Easton D, Sodha N, Seal S, Barfoot R, Mangion J, Chang-Claude J, Eccles D, Eeles R, Evans DG, Houlston R, Murday V, Narod S, Peretz T, Peto J, Phelan C, Zhang H X, Szabo C, Devilee P, Goldgar D, Futreal PA, Nathanson KL, Weber B, Rahman N, Stratton MR: Low-penetrance susceptibility to breast cancer due to CHEK2(*)1100delC in noncarriers of BRCA1 or BRCA2 mutations. Nat Genet 2002, 31:55-59.

7. Brose MS, Rebbeck TR, Calzone KA, Stopfer JE, Nathanson KL, Weber BL: Cancer risk estimates for BRCA1 mutation carriers identified in a risk evaluation program. J Natl Cancer Inst 2002, 94:1365-1372.

8. Thompson D, Easton DF: Cancer Incidence in BRCA1 mutation carriers. J Nat/ Cancer Inst 2002, 94:1358-1365.

9. Garber JE, Goldstein AM, Kantor AF, Dreyfus MG, Fraumeni JF Jr, Li FP: Follow-up study of twenty-four families with Li-Fraumeni syndrome. Cancer Res 1991, 51:6094-6097.

10. Brekelmans CT, Seynaeve C, Bartels CC, Tilanus-Linthorst MM, Meijers-Heijboer EJ, Crepin CM, van Geel AA, Menke M, Verhoog LC, van den Ouweland A, Obdeijn IM, Klijn JG: Effectiveness of breast cancer surveillance in BRCA1/2 gene mutation carriers and women with high familial risk. J Clin Oncol 2001, 19:924930.

11. Kuhl CK, Schmutzler RK, Leutner CC, Kempe A, Wardelmann E, Hocke A, Maringa M, Pfeifer U, Krebs D, Schild HH: Breast MR imaging screening in 192 women proved or suspected to be carriers of a breast cancer susceptibility gene: preliminary results. Radiology 2000, 215:267-279.

12. Claus EB, Risch N, Thompson WD: Genetic analysis of breast cancer in the cancer and steroid hormone study. Am J Hum Genet 1991, 48:232-242.

13. Gail MH, Brinton LA, Byar DP, Corle DK, Green SB, Schairer C, Mulvihill JJ: Projecting individualized probabilities of developing breast cancer for white females who are being examined annually. J Natl Cancer Inst 1989, 81:1879-1886.

14. Antoniou AC, Pharoah PD, McMullan G, Day NE, Stratton MR, Peto J, Ponder BJ, Easton DF: A comprehensive model for familial breast cancer incorporating BRCA1, BRCA2 and other genes. Br J Cancer 2002, 86:76-83.

15. Fisher B, Costantino JP, Wickerham DL, Redmond CK, Kavanah M, Cronin WM, Vogel V, Robidoux A, Dimitrov N, Atkins J, Daly M, Wieand S, Tan-Chiu E, Ford L, Wolmark N: Tamoxifen for prevention of breast cancer: report of the National Surgical Adjuvant Breast and Bowel Project P-1 Study. J Natl Cancer Inst 1998, 90:1371-1388.

16. Powles T, Eeles R, Ashley S, Easton D, Chang J, Dowsett M, Tidy A, Viggers J, Davey J: Interim analysis of the incidence of breast cancer in the Royal Marsden Hospital tamoxifen randomised chemoprevention trial. Lancet 1998, 352:98-101.

17. Veronesi U, Maisonneuve P, Costa A, Sacchini V, Maltoni C, Robertson C, Rotmensz N, Boyle P: Prevention of breast cancer with tamoxifen: preliminary findings from the Italian randomised trial among hysterectomised women. Italian Tamoxifen Prevention Study. Lancet 1998, 352:93-97.

18. Cuzick J, Forbes J, Edwards R, Baum M, Cawthorn S, Coates A, Hamed A, Howell A, Powles T: First results from the International Breast Cancer Intervention Study (IBIS-I): a randomised prevention trial. Lancet 2002, 360:817-824.

19. Papanicolaou GN, Holmquist DG, Bader GM, Falk EA: Exfoliative cytology of the human mammary gland and its value in the diagnosis of cancer and other diseases of the breast. Cancer 1958, 11:377-409.

20. Sartorius OW, Smith HS, Morris P, Benedict D, Friesen L: Cytologic evaluation of breast fluid in the detection of breast disease. J Natl Cancer Inst 1977, 59:1073-1080.

21. Wynder EL, Lahti H, Laakso K, Cheng SL, DeBevoise S, Rose DP: Nipple aspirates of breast fluid and the epidemiology of breast disease. Cancer 1985, 56:1473-1478.

22. Sauter ER, Babb J, Daly M, Engstrom PF, Ehya H, Malick J, Diamandis E: Prostate-specific antigen production in the female 
breast: association with progesterone. Cancer Epidemiol Biomarkers Prev 1998, 7:315-320.

23. Sauter ER, Ross E, Daly M, Klein-Szanto A, Engstrom PF, Sorling A, Malick J, Ehya, $\mathrm{H}$ : Nipple aspirate fluid: a promising noninvasive method to identify cellular markers of breast cancer risk. Br J Cancer 1997, 76:494-501.

24. Wrensch MR, Petrakis NL, Gruenke LD, Ernster VL, Miike R, King EB, Hauck WW: Factors associated with obtaining nipple aspirate fluid: analysis of 1428 women and literature review. Breast Cancer Res Treat 1990, 15:39-51.

25. Petrakis NL: Physiologic, biochemical, and cytologic aspects of nipple aspirate fluid. Breast Cancer Res Treat 1986, 8:7-19.

26. Krishnamurthy S, Sneige N, Thompson PA, Marcy SM, Singletary SE, Cristofanilli M, Hunt KK, Kuerer HM: Nipple aspirate fluid cytology in breast carcinoma. Cancer 2003, 99:97-104.

27. King EB, Chew KL, Petrakis NL, Ernster VL: Nipple aspirate cytology for the study of breast cancer precursors. J Natl Cancer Inst 1983, 71:1115-1121.

28. Dooley WC, Ljung BM, Veronesi U, Cazzaniga M, Elledge RM, O'Shaughnessy JA, Kuerer HM, Hung DT, Khan SA, Phillips RF, Ganz PA, Euhus DM, Esserman L, Haffty BG, King BL, Kelley MC, Anderson MM, Schmit PJ, Clark RR, Kass FC, Anderson BO, Troyan SL, Arias RD, Quiring JN, Love SM, Page DL, King EB: Ductal lavage for detection of cellular atypia in women at high risk for breast cancer. J Natl Cancer Inst 2001, 93:1624-1632.

29. Love SM, Barsky SH: Breast-duct endoscopy to study stages of cancerous breast disease. Lancet 1996, 348:997-999.

30. Dooley WC: Routine operative breast endoscopy during lumpectomy. Ann Surg Oncol 2003, 10:38-42.

31. Page DL, Dupont WD, Rogers LW, Rados MS: Atypical hyperplastic lesions of the female breast. A long-term follow-up study. Cancer 1985, 55:2698-2708.

32. Dupont WD, Parl FF, Hartmann WH, Brinton LA, Winfield AC, Worrell JA, Schuyler PA, Plummer WD: Breast cancer risk associated with proliferative breast disease and atypical hyperplasia. Cancer 1993, 71:1258-1265.

33. Wrensch MR, Petrakis NL, King EB, Miike R, Mason L, Chew KL, Lee MM, Ernster VL, Hilton JF, Schweitzer R: Breast cancer incidence in women with abnormal cytology in nipple aspirates of breast fluid. Am J Epidemiol 1992, 135:130-141.

34. Wrensch MR, Petrakis NL, Miike R, King EB, Chew K, Neuhaus J, Lee MM, Rhys M: Breast cancer risk in women with abnormal cytology in nipple aspirates of breast fluid. J Natl Cancer Inst 2001, 93:1791-1798.

35. Fabian CJ, Kimler BF, Zalles CM, Klemp JR, Kamel S, Zeiger S, Mayo MS: Short-term breast cancer prediction by random periareolar fine-needle aspiration cytology and the Gail risk model. J Nat/ Cancer Inst 2000, 92:1217-1227.

36. Foretova L, Garber JE, Sadowsky NL, Verselis SJ, Li FP: Prostate-specific antigen in nipple aspirate [letter]. Lancet 1996, 347:1631.

37. Mitchell G, Sibley PE, Wilson AP, Sauter E, A'Hern R, Eeles RA: Prostate-specific antigen in nipple aspiration fluid: menstrual cycle variability and correlation with serum prostate-specific antigen. Tumour Biol 2002, 23:287-297.

38. Sauter ER, Daly M, Linahan K, Ehya H, Engstrom PF, Bonney G, Ross EA, Yu H, Diamandis E: Prostate-specific antigen levels in nipple aspirate fluid correlate with breast cancer risk. Cancer Epidemiol Biomarkers Prev 1996, 5:967-970.

39. Zhao Y, Verselis SJ, Klar N, Sadowsky NL, Kaelin CM, Smith B, Foretova L, Li, FP: Nipple fluid carcinoembryonic antigen and prostate-specific antigen in cancer-bearing and tumor-free breasts. J Clin Oncol 2001, 19:1462-1467.

40. Kuerer HM, Thompson PA, Krishnamurthy S, Fritsche HA, Marcy SM, Babiera GV, Singletary SE, Cristofanilli M, Sneige N, Hunt KK: High and differential expression of HER-2/neu extracellular domain in bilateral ductal fluids from women with unilateral invasive breast cancer. Clin Cancer Res 2003, 9:601-605.

41. Connolly JM, Rose DP: Epidermal growth factor-like proteins in breast fluid and human milk. Life Sci 1988, 42:1751-1756.

42. Gann P, Chatterton R, Vogelsong K, Dupuis J, Ellman A: Mitogenic growth factors in breast fluid obtained from healthy women: evaluation of biological and extraneous sources of variability. Cancer Epidemiol Biomarkers Prev 1997, 6:421428.

43. Hsiung R, Zhu W, Klein G, Qin W, Rosenberg A, Park P, Rosato $E$, Sauter $E$ : High basic fibroblast growth factor levels in nipple aspirate fluid are correlated with breast cancer. Cancer $J$ 2002, 8:303-310.

44. Liu $\mathrm{Y}$, Wang JL, Chang $\mathrm{H}$, Barsky SH, Nguyen M: Breast-cancer diagnosis with nipple fluid bFGF [letter]. Lancet 2000, 356: 567.

45. Mannello F, Sebastiani M: Zymographic analyses and measurement of matrix metalloproteinase-2 and -9 in nipple aspirate fluids. Clin Chem 2003, 49:1546-1550.

46. Botti C, Pescatore B, Mottolese M, Sciarretta F, Greco C, Di Filippo F, Gandolfo GM, Cavaliere F, Bovani R, Varanese A, Cianciulli AM: Incidence of chromosomes 1 and 17 aneusomy in breast cancer and adjacent tissue: an interphase cytogenetic study. J Am Coll Surg 2000, 190:530-539.

47. Fehm T, Morrison L, Saboorian H, Hynan L, Tucker T, Uhr J: Patterns of aneusomy for three chromosomes in individual cells from breast cancer tumors. Breast Cancer Res Treat 2002, 75: 227-239.

48. Roka S, Fiegl M, Zojer N, Filipits M, Schuster R, Steiner B, Jakesz $\mathrm{R}$, Huber H, Drach J: Aneuploidy of chromosome 8 as detected by interphase fluorescence in situ hybridization is a recurrent finding in primary and metastatic breast cancer. Breast Cancer Res Treat 1998, 48:125-133

49. Tagawa Y, Yasutake T, lkuta Y, Oka T, Terada R: Chromosome 8 numerical aberrations in stage II invasive ductal carcinoma: correlation with patient outcome and poor prognosis. Med Oncol 2003, 20:127-136.

50. King BL, Tsai SC, Gryga ME, D'Aquila TG, Seelig SA, Morrison LE, Jacobson KK, Legator MS, Ward DC, Rimm DL, Phillips RF: Detection of chromosomal instability in paired breast surgery and ductal lavage specimens by interphase fluorescence in situ hybridization. Clin Cancer Res 2003, 9:1509-1516.

51. Yamamoto D, Senzaki H, Nakagawa H, Okugawa H, Gondo H, Tanaka K: Detection of chromosomal aneusomy by fluorescence in situ hybridization for patients with nipple discharge. Cancer 2003, 97:690-694.

52. Evron E, Umbricht CB, Korz D, Raman V, Loeb DM, Niranjan B, Buluwela L, Weitzman SA, Marks J, Sukumar S: Loss of cyclin D2 expression in the majority of breast cancers is associated with promoter hypermethylation. Cancer Res 2001, 61:27822787.

53. Sirchia SM, Ferguson AT, Sironi E, Subramanyan S, Orlandi R, Sukumar S, Sacchi N: Evidence of epigenetic changes affecting the chromatin state of the retinoic acid receptor beta2 promoter in breast cancer cells. Oncogene 2000, 19:15561563.

54. Evron E, Dooley WC, Umbricht CB, Rosenthal D, Sacchi N, Gabrielson E, Soito AB, Hung DT, Ljung B, Davidson NE, Sukumar S: Detection of breast cancer cells in ductal lavage fluid by methylation-specific PCR. Lancet 2001, 357:13351336.

55. Paweletz CP, Trock B, Pennanen M, Tsangaris T, Magnant C, Liotta LA, Petricoin EF III: Proteomic patterns of nipple aspirate fluids obtained by SELDI-TOF: potential for new biomarkers to aid in the diagnosis of breast cancer. Dis Markers 2001, 17: 301-307.

56. Sauter ER, Zhu W, Fan XJ, Wassell RP, Chervoneva I, Du Bois GC: Proteomic analysis of nipple aspirate fluid to detect biologic markers of breast cancer. $\mathrm{Br} J$ Cancer 2002, 86:14401443.

57. Kuerer HM, Goldknopf IL, Fritsche H, Krishnamurthy S, Sheta EA, Hunt KK: Identification of distinct protein expression patterns in bilateral matched pair breast ductal fluid specimens from women with unilateral invasive breast carcinoma. Highthroughput biomarker discovery. Cancer 2002, 95:2276-2282.

58. Varnum SM, Covington CC, Woodbury RL, Petritis K, Kangas LJ, Abdullah MS, Pounds JG, Smith RD, Zangar RC: Proteomic characterization of nipple aspirate fluid: identification of potential biomarkers of breast cancer. Breast Cancer Res Treat 2003, 80:87-97.

\section{Correspondence}

Dr Imogen Locke, Translational Cancer Genetics Team \& Cancer Genetics Unit, The Institute of Cancer Research and The Royal Marsden NHS Trust, Orchard House, Downs Road, Sutton, Surrey SM2 5PT, UK. Tel: +44 (0)20 8661 3375; fax: +44 (0)20 87701489 ; e-mail: imogen.locke@icr.ac.uk 